\title{
Analysis of risk factors for prolong hospitalization in chronic subdural hematoma undergoing single burr hole and drainage
}

\author{
Sumit Joshi $M S^{1}$, Prakash Paudel $F C P S^{2}$, Damber Bikram Shah $M S^{3}$, Prasanna Karki PhD ${ }^{4}$, Gopal Raman Sharma \\ $M S^{5}$ \\ 1,2,3,4,5 Department of Neurosciences, Nepal Mediciti, Lalitpur, Nepal
}

Date of submission: $7^{\text {th }}$ September 2020

Date of acceptance: $14^{\text {th }}$ February 2021

Date of publication: $1^{\text {st }}$ March 2021

\begin{abstract}
Introduction: Single burr hole surgery for Chronic subdural hematoma (CSDH) is commonly performed neurosurgical procedure with $>90 \%$ favorable outcome and less hospital stay. However, sometimes hospital stay may be prolonged due to associated prognostic factors, even in patients with favorable outcome. This study aims to analyze the early outcome of single burr hole and drainage surgery and factors that may be associated with prolong hospitalization.
\end{abstract}

Materials and method: A retrospective analysis of the patients who underwent single burr hole and drainage for CSDH from sept 2017 to may 2020 in Nepal Mediciti hospital. The patients with B/L CSDH, who underwent double burr hole and drainage or craniotomy evacuation or conservatively managed patients were excluded from the study. Early outcome was assessed using Glasgow outcome score at 7 days. Effect of use of antiplatelet/ anticoagulant drugs, age, comorbidity, preoperative Glasgow coma score on number of hospital stay was analyzed. Chi-square test was used for statistical analysis in SPSS version 25.

Results: Out of 85 patients, 73 were male. Mean age was 63.8 years. Early outcome in 7 days was favorable with GOS (4-5) in $90.6 \%$. The use of antiplatelet or anticoagulant drugs was more common amongst patients with age $>70$ years $(\mathrm{p}=0.01)$. The number of hospital stay was associated with age $(\mathrm{p}=0.00)$, antiplatelet or anticoagulant drugs $(\mathrm{p}=0.00)$, comorbidities $(\mathrm{p}=0.001)$, preoperative $\mathrm{GCS}(\mathrm{P}=0.001)$ and $\mathrm{GOS}$ at 7 days $(\mathrm{p}=0.001)$.

Conclusion: Single burr hole and drainage surgery for CSDH mostly produce favorable outcome. The use of antiplatelet or anticoagulant drugs is more common in patients above 70 years. Age, antiplatelet or anticoagulant drugs, comorbidities, preoperative GCS, GOS at 7 days are related with longer hospital stay.

Key words: chronic subdural hematoma, hospital stay, outcome, single burr hole and drainage

Access this article online

Website: https://www.nepjol.info/index.php/NJN

DOI: https://doi.org/10.3126/njn.v18i1.34938

HOW TO CITE

Joshi S, Paudel P, Shah DB, Karki P, Sharma GR. Analysis of risk factors for prolong hospitalization in chronic subdural hematoma undergoing single burr hole and drainage. NJNS. 2021;18(1):3944.

${ }^{1}$ ORCID id: 0000-0002-7883-9354

2ORCID id: 0000-0002-8830-3908

${ }^{3}$ ORCID id: 0000-0002-5707-7696

${ }^{4}$ ORCID id: 0000-0003-1469-3517

${ }^{5}$ ORCID id: 0000-0003-3638-4993

Address for correspondence:

Dr Sumit Joshi

Nepal Mediciti,

Sainbu, Bhaisepathi, Lalitpur

E-mail: neuro2004@live.com

Phone: +977-9851017698

Copyright (C) 2021 Nepalese Society of Neurosurgeons (NESON)

ISSN: 1813-1948 (Print), 1813-1956 (Online)

\section{Introduction}

\begin{abstract}
Chronic subdural hematoma (CSDH) is most commonly encountered entity in neurosurgical practice predominantly affecting the elderly population and is one of the most gratifying surgeries as most of the time there is dramatic postoperative improvement of symptoms. $\mathrm{CSDH}$ is one of the most common types of intracranial hemorrhage and is caused by a tear in the bridging vein due to minor head trauma ${ }^{1}$ but many people do not recall any trauma to the head and even if they had one, it is often trivial. Coagulopathy, brain surgeries and brain hypotension are also well known cause for $\mathrm{CSDH} .{ }^{2,3,4}$ Old age, antiplatelet medication, anticoagulant medication, diabetes mellitus (DM), end-stage renal disease (ESRD), coagulopathy, Glasgow Coma Scale (GCS) score,
\end{abstract}




\section{Joshi et al}

hematoma thickness and bilaterality of the hematoma are all well-known prognostic factors correlated with the outcome of burr hole drainage. ${ }^{5,6,7,8}$ The overall incidence rate of CSDH has been reported to be 20.6/100,000/year, with 76.5 in the age group of 70-79 years and 127.1 in the over 80 years group. ${ }^{9}$ There is steady increase in the incidence of CSDH in developing countries due to the rise in life expectancy. ${ }^{10}$ The single burr hole and drainage for CSDH is one of the easy, safe and effective technique, which is commonly performed neurosurgical procedure ${ }^{11}$. Complications may vary from minor Pneumocephalus, seizure to major complications like intracerebral hemorrhage and subdural empyema. ${ }^{12}$ Different study has shown that mean hospital stay following single burr hole surgery to be $3.68 \pm 2.6,4.3 \pm 2.2$ days with $>90 \%$ of the patients with favorable outcome GOS (4-5). ${ }^{13}$ In general, excellent postoperative outcome is expected and patients are discharged earlier than 7days. Although this is general concept, sometimes some patients may need long term hospitalization, identification of these factors associated with prolong hospital stay is very important and should never be overshadowed. However, occasionally even patients with good outcome may need prolong hospital stay. In this study early outcome following single burr hole and drainage surgery and factors associated with prolong hospital stay ( $>7$ days) will be evaluated.

\section{Materials and Method}

Retrospective study was conducted in all patients who underwent single burr hole and drainage for CSDH from sept 2017 to may 2020 in Nepal Mediciti Hospital. The patients with bilateral CSDH, who underwent bilateral or double burr hole and drainage or craniotomy and evacuation or conservatively managed patients were excluded from the study. After authorization from the Institutional review committee (IRC), IRC-RP-2076/0016, data was collected from hospital medical record and entered in Proforma. The early outcome was measured using Glasgow Outcome Scale (GOS) on seventh day. Those who were discharged in earlier than seven days were followed up in OPD on $7^{\text {th }}$ day and GOS was recorded. The outcome was dichotomized into favorable (4-5) and unfavorable (1-3). The number of hospital stay was dichotomized into $\leq 7$ days (early) and $>7$ days (prolong) and it's association with the independent variables like age $<70$ years and $>70$ years, presenting Glasgow Coma Scale (GCS) $(<9$, $9-13,14-15)$, GOS at 7 days $\{(3-4)$ favorable and (1-3) unfavorable\}, antiplatelet and anticoagulant medications and comorbidities was analyzed. The association of use of antiplatelet or anticoagulant drugs with age $>70$ and $<$ 70 was also analyzed.

\section{Statistical analysis}

Statistical analysis was done by IBM SPSS statistic 25 for windows using chi-square and type 1 error is set as 0.05 .

\section{Results}

There were 85 patients, of which 73 were males. Mean age was 63.8 years. At one week after surgical evacuation, $77(90.6 \%)$ had favorable outcome (Table 1). There was a single mortality $(1.17 \%)$ in our series.

\begin{tabular}{|c|c|c|c|c|}
\hline Outcome & GOS & Frequency & Percent & \\
\hline \multirow{2}{*}{ Unfavorable } & 1 & 0 & $0 \%$ & $9.4 \%$ \\
& 2 & 1 & $1.2 \%$ & \\
\hline \multirow{2}{*}{ Favorable } & 3 & 7 & $8.2 \%$ & \\
& 5 & 18 & $21.2 \%$ & $90.6 \%$ \\
\hline Total & 5 & 59 & $69.4 \%$ & \\
\hline
\end{tabular}

Table 1: Early outcome in one week

The use of antiplatelet or anticoagulant drugs were more common in $>70$ years $(p=0.014)$ (See Table 2$)$.

\begin{tabular}{c|c|c|c|c}
\hline \multirow{2}{*}{ AGE } & \multicolumn{2}{|c|}{$\begin{array}{c}\text { Antiplatelet or } \\
\text { Anticoagulant }\end{array}$} & Total & \\
& No & Yes & & \\
\hline$<70$ years & 39 & 21 & 60 & P value \\
\hline$>70$ years & 9 & 16 & 25 & 0.014 \\
\hline Total & 48 & 37 & 85 & \\
\hline
\end{tabular}

Table 2: Association of antiplatelet and anticoagulant drugs with age

In 49 patients, the number of hospital stay was $\leq$ 7 days. Prolong hospital stay ( $>7$ days) was significantly associated with age $(<70$ years $)(p=0.000)$, antiplatelet or anticoagulant drugs use $(\mathrm{p}=0.000)$, Comorbidity $(\mathrm{p}=0.001), \operatorname{GCS}(\mathrm{p}=0.001)$ and GOS $(\mathrm{p}=0.001)$ (See Table 3). 
Prolong hospital stay following evacuation of chronic SDH

\begin{tabular}{|c|c|c|c|c|c|}
\hline \multirow{2}{*}{\multicolumn{2}{|c|}{ Independent Variables }} & \multicolumn{2}{|c|}{$\begin{array}{c}\text { Dependent variable } \\
\text { (Number of hospital stay) }\end{array}$} & \multirow[t]{2}{*}{ Total } & \multirow[t]{2}{*}{ P value } \\
\hline & & $<7$ days & $>7$ days & & \\
\hline \multirow{2}{*}{ Age } & $<70$ & 37 & 11 & 48 & \multirow{3}{*}{0.000} \\
\hline & \multirow[t]{2}{*}{$>70$} & 12 & 25 & 37 & \\
\hline Total & & 49 & 36 & 85 & \\
\hline Antiplatelet & No & 49 & 11 & 60 & \multirow{3}{*}{0.000} \\
\hline Anticoagulant & Yes & 0 & 25 & 25 & \\
\hline Total & & 49 & 36 & 85 & \\
\hline \multirow{2}{*}{ Comorbidity } & No & 42 & 19 & 61 & \multirow{3}{*}{0.001} \\
\hline & Yes & 7 & 17 & 24 & \\
\hline Total & & 49 & 36 & 85 & \\
\hline \multirow{3}{*}{ GCS } & $14-15$ & 47 & 23 & 70 & \multirow{4}{*}{0.001} \\
\hline & $9-13$ & 2 & 12 & 14 & \\
\hline & $<9$ & 0 & 1 & 1 & \\
\hline Total & & 49 & 36 & 85 & \\
\hline \multirow{2}{*}{ GOS } & $4-5$ & 49 & 28 & 77 & \multirow{3}{*}{0.001} \\
\hline & $1-3$ & 0 & 8 & 8 & \\
\hline Total & & 49 & 36 & 85 & \\
\hline
\end{tabular}

Table 3: Association length of hospital stay with independent variables

\section{Discussion}

CSDH is a diagnosis with increasing prevalence among the older age. With steady increase in the life expectancy in the developing countries, in last decade we have witnessed increase in the incidence of CSDH. Surgery is very rewarding as most of the time there is dramatic improvement in the clinical symptoms and post-operatively high yield appreciation are always expected. The preferred surgical method continues to attract debate. There is lack of uniformity about the treatment strategies, such as the role of burr hole, twist drill, craniotomy etc. There is also disagreement about the use of drain, irrigation and steroid. ${ }^{14,15}$ All patients in our series underwent single burr hole and drainage under General anesthesia except one patient with CKD who was operated under sedation. All were post-operatively kept in flat position for 48 hours. Majority of the patients received antibiotic for seven days, intravenously for at least 48 hours and then replaced with oral antibiotics. Majority of the patients (49) were discharged earlier than 7 days following burr hole evacuation. Identification of factors leading to prolonged hospitalization is very essential while evaluating and have to be explained during preoperative counseling. The additional expense of hospitalization and unplanned stress which follows due to prolonged hospital invite disappointment and dissatisfaction.

In our series at one week, 77 (90.6\%) had favorable outcome with GOS (4-5), which was comparable with other series. ${ }^{13} \mathrm{CSDH}$ is usually the disease of the old age though it may occur in other age group also but etiology may vary. Cerebral atrophy associated with ageing is the major factor that makes the elderly susceptible to develop CSDH. ${ }^{16}$ Shrinkage of the brain leads to easier separation of dura from the arachnoid following a minor trauma or stress and lack of tamponade effect of the brain on the hematoma leads to expansion of the hematoma. ${ }^{17}$ Clinical symptoms of CSDH appear to vary depending on the degree of intracranial pressure from a symptomatic to comatose. Besides, headache, speech, sensorimotor disturbance, altered behavior or seizure may occur. ${ }^{18}$ Recurrent falls, delirium and worsening cognition were the most common symptoms in the old age $>70$ years $^{19}$ whereas the younger population are more likely to present with headache, nausea and vomiting as a consequence of raised intracranial pressure likely explained by a mass effect without significant age-related atrophy and the symptoms arrive earlier (smaller hematomas) and apparently before neurological deficits occur in most cases. ${ }^{20}$ In our series of the 36 patients who were discharged more than 7 days, 25 were $>70$ years of age $(p=0.000)$. Recovery in different age group varies, as morbidity and mortality are more associated with older age groups. Frailty, degenerative changes in the musculoskeletal system and nervous system, hemodynamic alteration, compromised respiratory system, recovery from anesthesia, postoperative delirium, postoperative cognitive dysfunction (POCD), delayed wound healing are independent factors associated with old age following surgery and may not be associated with the disease. ${ }^{21}$ These individual factors may limit functional outcome and recovery time in patients with increasing age and prolong hospital stay. Age itself and 
other medical conditions are the pre-existing comorbidity that can have direct role in the patient's recovery time. Only 7/49 patients discharged in $\leq 7$ days had comorbidity Hypertension (HTN), Diabetes Mellitus (DM), COPD whereas 17/36 patients who were discharged in >7days had HTN, uncontrolled DM, COPD, Post-MI, CKD, PCI (percutaneous coronary intervention), AF (atrial fibrillation), ischemic stroke $(\mathrm{p}=0.000)$. Optimization of the medical comorbid condition is very important for the outcome following of any surgery which may inversely delay the recovery time and hospital stay.

In the last decade there has been an increasing use of antiplatelet and anticoagulation therapy among adult patients especially in the elderly. ${ }^{22}$ This has also been encouraged by an increasing number of studies showing the clinical and economical advantage of aspirin consumption both for primary and secondary prevention of cardiovascular disease (CVD), as well as for cancer prevention. ${ }^{23,24,25,26,27,28}$ Bleedings are well known risks of both antiplatelet and anticoagulant therapy and both therapies have historically been considered as risk factors for CSDH. ${ }^{29,30,31,32,33}$ There was significant association of use of antiplatelet or anticoagulant in elder group in our series, 21 out of 60 in age group $<70$ years and 16 out of 25 in age group $>70$ years were on antiplatelet or anticoagulation therapy $(\mathrm{p}=0.014)$. In all elective cases, aspirin or anticoagulant drug like warfarin was stopped for 3 days prior to surgery. Vitamin $\mathrm{K}$ was administered I/V for 3 days in patients with warfarin and Platelet rich plasma was transfused if platelet count was $<90$ thousands. The surgery was performed only after normalization of PT/ INR and platelet count. In case of emergency I/V Vitamin $\mathrm{K}$, platelet rich plasma or Fresh frozen plasma was transfused intra operatively for therapeutic correction and continued postoperatively until achieved. Postoperatively, aspirin or warfarin was started only after 3- 5 days, after getting a postoperative CT scan. Sometimes in patients with cardiac stent anticoagulants can't be stopped as there is chance of thrombosis. There was one patient in our series also, where warfarin was switched to heparin (as reversal is quick), aPTT (activated partial thromboplastin time) was monitored as per protocol and later switched to oral anticoagulant. None of the patients in our series discharged $\leq 7$ days were on antiplatelet or anticoagulant drugs whereas 17 out of 36 discharged in $>7$ days were on antiplatelet or anticoagulant drugs $(\mathrm{p}=0.001)$.

Different studies have demonstrated the association of preoperative GCS with the outcome using GOS. Islam et al, showed statistically significant correlation between GCS on admission and clinical outcome in patients with unilateral chronic subdural hematoma after surgery. ${ }^{34}$ Outcome is directly related to the length of hospital stay.
In our series, of the 49 patients discharged $\leq 7$ days, 47 had GCS (4-15), 2(9-13) and $0(<9)$. Among 36 patients discharged $>7$ days, 23 had GCS(14-15),12(9-13), $1(<9)$ $(\mathrm{p}=0.001)$. The preoperative GCS determined the outcome and is significantly associated with the number of hospital stay. Out of 49 patients discharged in $\leq 7$ days 49 had favorable GOS(4-5) and 36 patients discharged $>7$ days 28 had favorable GOS(4-5) and 4 unfavorable $\operatorname{GOS}(1-3)(\mathrm{p}=0.001)$. Most of the patients with favorable GOS are discharged in $\leq 7$ days, sometimes even patients with favorable GOS may need prolong hospitalization due to some medical problems surgical complication.

Though new onset of medical problems and surgical complications are also directly associated with the recovery time and length of hospital stay but it can't be predicted pre-operatively. The surgical complications may vary from minor common complication like pneumocephalus, seizure to severe ones like intracerebral hemorrhage, subdural empyema and medical problems like chest infection, UTI and DVT. As our study is more focused on determining the cause of prolong hospital stay, these were not studied. This being a retrospective study; larger sample size and prospective study is needed to establish the findings of this study.

\section{Conclusion}

Single burr hole and drainage for CSDH mostly produce favorable outcome. The use of antiplatelet or anticoagulant drugs is more common in patients older than 70 years. Age, antiplatelet or anticoagulant drugs, comorbidities, preoperative GCS, GOS at 7 days are associated factors that may be related with longer hospital stay. Incorporation of the prognostic factors are very essential and should not be omitted while explaining the prognosis.

\section{Source of financial support: None Conflict of interest: None}

\section{References}

1. Kageyama H, Toyooka $\mathrm{T}$, Tsuzuki $\mathrm{N}$, et al. Nonsurgical treatment of chronic subdural hematoma with tranexamic acid. J Neurosurg.2013; 119:332337. https://doi.org/10.3171/2013.3.JNS122162.

2. Baechli H, Nordmann A, Bucher HC, et al. Demographics and prevalent risk factors of chronic subdural haematoma: results of a large single-center cohort study. Neurosurg Rev .2004;27(4):263-6. https://doi.org/ 10.1007/s10143-004-0337-6. 
3. Inamasu J, Watabe $\mathrm{T}$, Ganaha $\mathrm{T}$, et al. Clinical characteristics and risk factors of chronic sub- dural haematoma associated with clipping of unruptured cerebral aneurysms J Clin Neurosci. 2013; 20(8):10958. https://doi.org/10.1016/j.jocn.2012.09.024.

4. Xia P, Hu XY, Wang J, et al. Risk factors for subdural haematomas in patients with spontaneous intracranial hypotension. PLoS ONE.2015; 10(4). https://doi. org/10.1371/journal.pone.0123616.

5. Delgado PD, Cogolludo FJ, Mateo O, et al. Early prognosis in chronic subdural hematomas. Multivariate analysis of 137 cases. Rev Neurol. 2000; 1(15); 30(9):811-7. PMID: 10870192.

6. Lee KS: Chronic subdural hematoma in the aged, trauma or degeneration? .J Korean Neurosurg Soc. 2016; 59(1):1-5. https://doi.org/10.3340/ jkns.2016.59.1.1.

7. Wang IK, Cheng YK, Lin CL, et al. Comparison of Subdural Hematoma Risk between Hemo- dialysis and Peritoneal Dialysis Patients with ESRD. Clin J Am Soc Nephrol .2015; 10:994-1001. https://doi. org/10.2215/CJN.08140814

8. Hiromichi Y, Yutaka H, Hideo H, et la. Independent predictors of recurrence of chronic sub- dural hematoma: results of multivariate analysis performed using a logistic regression model. J Neurosurg. 2003; 98(6):1217-21. https://doi.org/10.3171/ jns.2003.98.6.1217.

9. Aristedis R, Spyridon T, Dimitrios P. Chronic subdural hematoma: surgical management and outcome in 986 cases. A classification and regression tree approach. Surg neurology Int .2015; 6:127. https://doi.org/10.4103/2152-7806.161788.

10. Hiroshi K, Motonobu K, Makoto K, et al: Epidemiology of chronic subdural hematomas. No Shinkei Geka. 2011; 39(12):1149-53. PMID: 22128269.

11. Mersha A, Abat S, Temesgen T, et al. Outcome of Chronic Subdural Hematoma Treated with Single Burr Hole Under Local Anesthesia. Ethiop J Health Sci. 2020; 30(1):101-106. https://doi.org/10.4314/ ejhs.v30i1.13

12. Rohde V, Graf G, Hassler W. Complications of burrhole craniostomy and closed- system drainage for chronic subdural hematomas: a retrospective analysis of 376 patients. Neurosurgical Review. 2002; 25: 8994. https://doi.org/10.1007/s101430100182.

13. Abebe M, Sahlu A, Tsegaye T, et al. Outcome of Chronic Subdural Hematoma Treated with Single Burr Hole under Local Anesthesia. Ethiop J Health Sci. 2020; 30(1): 101-106. https://doi.org/10.4314/ ejhs.v30i1.13.
14. Santarius T, Lawton R, Kirkpatrick PJ, et al. The management of primary chronic subdural haematoma: A questionnaire survey of practice in the United Kingdom and the Republic of Ireland. Br J Neurosurg .2008; 22:529-34. https://doi. org/10.1080/02688690802195381.

15. Aleksa C, Mohit B, Kesava R. Management of chronic subdural hematoma: A national survey and literature review. Can J Neurol Sci. 2005; 32(4):5016. https://doi.org/10.1017/S0317167100004510.

16. Yang AI, Balser DS, Mikheev A, et al. Cerebral atrophy is associated with development of chronic subduralhaematoma. Brain Inj. 2012; 26(13-14): 1731-1736. https://doi.org/10.3109/02699052.2012. 698364

17. Markwalder TM. Chronic subdural hematomas: a review. J Neurosurg. 198; 54(5):637-45. https://doi. org/10.3171/jns.1981.54.5.0637.

18. Hiroshi K, Motonobu K, Makoto K, et al. Epidemiology of chronic subdural hematomas. No Shinkei Geka. 2011; 39(12):1149-53. PMID: 22128269

19. Gelabert-Gonzalez M, Iglesias-Pais M, Garcia-Allut A, et al. Chronic subdural haematoma. surgical treatment and outcome in 1000 cases. Clin Neurol Neurosurg. 2005; 107 (3):223-9. https://doi.org/ 10.1016/j.clineuro.2004.09.015.

20. Jiri Bartek J, Kristin S, Sanjay D, et al . Clinical Course in Chronic Subdural Hematoma Patients Aged 18-49 Compared to Patients 50 Years and Above: A Multicenter Study and Meta-Analysis. Front. Front Neurol. 2019; 5: 10:311. https://doi.org/10.3389/ fneur.2019.00311.

21. Stacie D, Jeffrey H S. LONG-TERM OUTCOMES IN ELDERLY SURGICAL PATIENTS. Mt Sinai J Med. 2012 j; 79(1): 95-106. https://doi.org/10.1002/ msj. 21288.

22. Flaherty ML, Kissela B, Woo D, et al. The increasing incidence of anticoagulant-associated intracerebral hemorrhage. Neurology. 2007; 68(2):116-21. https:// doi.org/10.1212/01.wnl.0000250340.05202.8b.

23. Benamouzig R, Uzzan B, Little J, et al. Low dose aspirin, COXinhibition and chemoprevention of colorectal cancer. February 2005Current Topics in Medicinal Chemistry 2005; 5(5):493-503. https://doi. org/10.2174/1568026054201631.

24. Jeffrey S B, Maria C R, Fausto A, et al. Aspirin for the primary prevention of cardiovascular events in women and men: a sex-specific meta-analysis of randomized controlled trials. JAMA. 2006; 295(3):306-13. https:// doi.org/ 10.1001/jama.295.3.306. 


\section{Joshi et al}

25. Flossmann E, Rothwell PM. Effect of aspirin on longterm risk of colorectal cancer: consistent evidence from randomised and observational studies. Lancet. 2007; 369(9573):1603-13. https://doi.org/10.1016/ S0140-6736(07)60747-8.

26. Sanmuganathan PS, Ghahramani P, Jackson PR, et al. Aspirin for primary prevention of coronary heart disease: safety and absolute benefit related to coronary risk derived from meta-analysis of randomised trials. Heart. 2001; 85(3):265-71. http://dx.doi.org/10.1136/ heart.85.3.265

27. Michael J T, Eric J J. Carlo P .The role of aspirin in cancer prevention. NatRev Clin Oncol.2012;9(5):25967. https://doi.org/10.1038/nrclinonc.2011.199

28. Kiichiro T, Ataru I, Keita F, et al. A health economic evaluation of aspirin in the primary prevention of cardiovascular disease in Japan. Internal Medicine .2007; 46(4). 157-162.DOI https://doi.org/10.2169/ internalmedicine.46.1843.

29. Baechli H, Nordmann A, Bucher HC, et al. Demographics and prevalent risk factors of chronic subdural haematoma: results of a large single-center cohort study. Neurosurg Rev. 2004; 27(4):263-6. https://doi.org/10.1007/s10143-004-0337-6.
30. Hart RG, Boop BS, Anderson DC. Oral anticoagulants and intracranial hemorrhage. Facts and hypotheses. Stroke. 1995; 26(8):1471-7. https:// doi.org/10.1161/01.STR.26.8.1471

31. Lindvall P, Koskinen LO. Anticoagulants and antiplatelet agents and the risk of development and recurrence of chronic subdural haematomas. J Clin Neurosci. 2009; 16(10):1287-90. https://doi. org/10.1016/j.jocn.2009.01.001

32. Reymond MA, Marbet G, Radu EW, et al. Aspirin as a risk factor for hemorrhage in patients with head injuries. Neurosurg Rev. 1992; 15(1):21-5. https:// doi.org/10.1007/BF02352062.

33. Rust T, Kiemer N, Erasmus A. Chronic subdural haematomas and anticoagulation or anti-thrombotic therapy. J Clin Neurosci. 2006; 13(8):823-7. https:// doi.org/10.1016/j.jocn.2004.12.013

34. Islam KM, Hasan M, Das S, Mahmood E, Barua $\mathrm{K}$. Correlation between Glasgow coma scale on admission and clinical outcome of patients with unilateral chronic subdural hematoma after surgery. Bangabandhu Sheikh Mujib Medical University Journal.2017; 10:115-18. https://doi.org/10.3329/ bsmmuj.v10i2.32711. 